\title{
PERFIL DE HABILIDADES E COMPETÊNCIAS NAS ATIVIDADES EXTRACURRICULARES DO CURSO DE ENGENHARIA AEROESPACIAL
}

Arthur Henrique Izumi de Abreu - arthurizumi@gmail.com

Universidade Federal de Minas Gerais (UFMG).

Rua Cid Rabelo Horta 127, Gameleira

30510-115 - Belo Horizonte - Minas Gerais

Darlan Vale Bayão - darlanvalebayao@gmail.com *

Universidade Federal de Minas Gerais (UFMG).

Rua Atalaia, 120 - Apto 120 - Caiçaras.

30770-470 - Belo Horizonte - Minas Gerais

Daniel Brandão de Angelis - daniel.angelis@yahoo.com.br

CEFET-MG

Rua Expedicionário Misael de Freitas, 177 - Caiçara

30750-470 - Belo Horizonte - Minas Gerais

Resumo: As atividades extracurriculares vêm desempenhando um papel fundamental no desenvolvimento/aperfeiçoamento de algumas competências e habilidades na formação do aluno de engenharia. Esse trabalho visa entender quais atividades impactam mais no desenvolvimento de determinadas habilidades do aluno. O perfil do aluno que busca participar de atividades fora do escopo de sala de aula é de um aluno que se importa pouco com o desempenho acadêmico, e que busca ser leal a uma equipe a qual fará parte e ter um nível de comprometimento e motivação que possibilite a ele ter bons resultados nas tarefas que venha a desempenhar.

Palavras-chave: Competências e habilidades. Atividades extracurriculares. Curso de engenharia aeroespacial.

\section{INTRODUÇÃO}

Para uma boa formação do engenheiro durante os estudos na universidade, é necessário desenvolver habilidades que vão além das disciplinas lecionadas em sala de aula. Segundo Ferreira (1999), é importante compreender quais são as principais habilidades e competências desejadas para uma boa atuação do engenheiro, e em seguida desenvolver tais habilidades em conjunto com a formação técnica do estudante.

No âmbito do curso de engenharia aeroespacial da Universidade Federal de Minas Gerais (UFMG) são apresentadas 4 principais atividades ditas "extracurriculares" a fim de complementar a formação do estudante de engenharia, são elas: Aerodesign, AeroJr, Divisão de propulsão e espaço (DPE) e Grêmio estudantil.

O Aerodesign é uma equipe de alunos que visa projetar e construir um aeromodelo de acordo com os requisitos das competições organizadas pelo SAE-Brasil Aerodesign (Society 
of Automotive Engineers do Brasil). A AeroJr é classificada como uma empresa júnior dentro do curso de engenharia aeroespacial prestando serviços de consultoria em engenharia e desenvolve projetos para entidades empresas e para a comunidade em geral, utilizando a estrutura da universidade e sob a orientação de professores e profissionais especializados.

O DPE é um grupo de alunos do curso de Engenharia Aeroespacial que tem como objetivo desenvolver conhecimentos na área de foguetemodelismo, espaçomodelismo e foguetismo. A equipe tem como principal missão desenvolver um protótipo de foguete seguindo os requisitos das competições organizadas pela IREC (Intercollegiate Rocket Engineering Competition). O grêmio estudantil dos alunos de engenharia aeroespacial (GRAERO) tem como papel principal representar os interesses dos discentes perante as reuniões do colegiado, e dos alunos do curso em relação aos diretórios acadêmicos e congregações da escola de engenharia. Tem como função secundária promover a harmonia, a boa convivência e a integração dos alunos.

Dentro dessas atividades extracurriculares são desenvolvidas diferentes competências e habilidades de acordo com a especificidade de cada atividade. Muitas dessas qualidades não são possíveis de serem adquiridas dentro da grade curricular obrigatória do curso. Eis que essas atividades desempenham um papel essencial na formação do aluno como engenheiro.

\subsection{Objetivo geral}

Quantificar as habilidades e competências que são mais relevantes e aprimoradas nas principais atividades extracurriculares do curso de engenharia aeroespacial.

\subsection{Objetivo especifico.}

Aplicar um questionário com uma lista de habilidades e competências no qual o aluno participante de alguma atividade extracurricular, atribuirá um nível de importância para a mesma e em seguida correlacionar a importância daquela atividade na sua formação de engenheiro. Criar um perfil de competências e habilidades comum aos alunos que participaram/participam de alguma atividade extracurricular sob o ponto de vista dos próprios entrevistados.

\section{MATERIAIS E MÉTODOS}

Para esse trabalho foi feita uma pesquisa quantitativa, utilizando um questionário, composto por várias assertivas nas quais o entrevistado atribuía um grau de importância para cada competência e habilidade listada. Foram 76 entrevistas ao todo dentre os alunos regularmente matriculados no curso de engenharia aeroespacial no ano de 2015. Nos quais 36 pertenciam ao Aerodesign, 14 pertencentes a AeroJr, 15 pelos alunos da DPE e 10 por alunos pertencentes ao grêmio. Se um aluno pertencesse a mais de uma atividade extracurricular, ele podia responder o questionário mais de uma vez, com o olhar de acordo com a determinada atividade.

\subsection{Avaliação das repostas do questionário.}

O questionário foi aplicado via google forms que é uma ferramenta online de preenchimento de formulários. Primeiro era apresentado ao aluno a identificação da competência e habilidade e em seguida a descrição do que se trata aquelas. Foi utilizada a escala Likert para transformar esses dados em números e assim ter uma ideia melhor das 
tendências comportamentais das amostras e população. Este questionário foi desenvolvido pelo autor, com base nos estudos de outros autores.

Na sequência o aluno atribuía um grau de importância podendo ser "sem importância", "pouco importante", "importante", "muito importante" ou extremamente importante. A cada grau de importância será então atribuído uma nota de 1 a 5 de acordo com o quadro 1 . As notas foram então somadas e retiradas a média aritmética simples, para então ter uma ideia da opinião de todos os membros de cada atividade.

Quadro 1 - Atribuição de valores para o grau de importância.

\begin{tabular}{l|l}
\hline Sem importância (Grau:1) & - Grau menor ou igual a 1,8 = Sem Importância. \\
\hline -Pouco Importante (Grau:2) & $\begin{array}{l}\text { - Grau maior que } 1,8 \text { e menor ou igual a } 2,6=\text { Pouco } \\
\text { Importante. }\end{array}$ \\
\hline -Importante (Grau:3) & $\begin{array}{l}\text { - Grau maior que } 2,6 \text { e menor ou iguais a } 3,4 \\
\text { Importante. }\end{array}$ \\
\hline -Muito importante (Grau:4) & $\begin{array}{l}\text { - Grau maior que } 3,4 \text { e menor que } 4,2=\text { Muito } \\
\text { Importância. }\end{array}$ \\
\hline $\begin{array}{l}\text {-Extremamente } \\
\text { (Grau:5) }\end{array}$ & $\begin{array}{l}\text { importante } \\
\text { importante. }\end{array}$ \\
\hline
\end{tabular}

Foi gerado gráficos de barras para comparar a opinião dos alunos (média do grau de importância) e as diversas habilidades e competências. Sendo cada atividade extracurricular representada por uma cor. As linhas vermelhas delimitam: "EI", "MI", "I", "PI" e "SI" que representam extremamente importante, muito importante, importante, pouco importante e sem importância respectivamente.

\subsection{Perguntas do questionário.}

Nas tabelas a seguir estão representados os grupos de perguntas por áreas, sendo elas: "Conhecimentos teóricos", "Conhecimentos técnicos e de engenharia", "Conhecimentos de ferramentas", "Qualidades pessoais" e "Trabalho em equipe".

Conhecimentos teóricos não são requisitos para se entrar em nenhuma das atividades supracitadas, mas é de grande importância no processo de aprendizado do aluno durante a atividade.

Tabela 1 - Conhecimentos teóricos.

\begin{tabular}{l|l}
\hline Competência e habilidade & Descrição. \\
\hline Fundamentos em ciências & $\begin{array}{l}\text { Conhecimentos das leis básicas, conceitos, teorias e } \\
\text { princípios, e capacidades de entender outras ciências, } \\
\text { química, biologia... }\end{array}$ \\
\hline $\begin{array}{l}\text { Conhecimento na área de } \\
\text { atuação }\end{array}$ & $\begin{array}{l}\text { Ter conhecimento sobre aviões, foguetes, gestão empresarial } \\
\text { e estudantil }\end{array}$ \\
\hline Habilidade em pesquisa & $\begin{array}{l}\text { Ser capaz de obter e avaliar as informações, conhecer } \\
\text { instrumentos de pesquisa e de busca de informações }\end{array}$ \\
\hline Equações matemáticas & $\begin{array}{l}\text { Capacidade de aplicar e entender equações matemáticas } \\
\text { envolvidas na atividade }\end{array}$ \\
\hline
\end{tabular}


"Os desafios para formar hoje o engenheiro do amanhã"

\begin{tabular}{l|l}
\hline Probabilidade e Estatística & $\begin{array}{l}\text { Capacidade de analisar e entender de forma lógica um } \\
\text { conjunto de dados }\end{array}$ \\
\hline Rendimento semestral global & Ter RSG maior que 3 (média das notas acima de 70\%) \\
\hline \multicolumn{1}{c}{ Fonte: Próprio autor }
\end{tabular}

De acordo com Silva (1999) esse grupo de conhecimentos estarão presentes no dia a dia de trabalho de um profissional de engenharia, e na Tabela 2 está descrito como conhecimento técnico e de engenharia.

Tabela 2 - Conhecimento técnico e de engenharia

\begin{tabular}{l|l}
\hline Competência e habilidade & Descrição. \\
\hline Conhecimento de projeto: & $\begin{array}{l}\text { Planejamento, estruturação, cálculos de cargas, atender a } \\
\text { requisitos }\end{array}$ \\
\hline $\begin{array}{l}\text { Conhecimento em técnicas } \\
\text { de processos de fabricação }\end{array}$ & $\begin{array}{l}\text { Montagem, laminação, soldagem, usinagem, colagem, } \\
\text { estampagem, recortes... }\end{array}$ \\
\hline $\begin{array}{l}\text { Conhecimento em montagem } \\
\text { e condução de experimentos }\end{array}$ & Capacidade de criar experimentos para testar as hipóteses \\
\hline Conhecimento de custos & $\begin{array}{l}\text { Conhecer custo envolvidos em uma atividade, como custo de } \\
\text { peças, equipamentos, consultorias jurídicas e empresariais... }\end{array}$ \\
\hline Práticas de engenharia & $\begin{array}{l}\text { A capacidade prática de aplicar ferramentas tecnológicas para } \\
\text { a criação e o desenvolvimento de novos produtos }\end{array}$ \\
\hline $\begin{array}{l}\text { Identificação e Resolução de } \\
\text { problemas }\end{array}$ & $\begin{array}{l}\text { (Habilidade em diagnosticar e resolver problemas, propor } \\
\text { hipóteses e soluções criativas e diversas para o problema) }\end{array}$ \\
\hline
\end{tabular}

Na tabela 3 está representada o grupo de conhecimento de ferramentas. De acordo com Silva (1999) este grupo de conhecimento está presente no desenvolvimento do indivíduo desde o seu nascimento, e são geralmente aprimorados quando colocados em prática.

Tabela 3 - Conhecimento de ferramentas

\begin{tabular}{l|l}
\hline \multicolumn{1}{c|}{ Competência e habilidade } & \multicolumn{1}{c}{ Descrição. } \\
\hline Conhecimento em língua portuguesa & Fala, escrita, redação... \\
\hline Conhecimento em língua estrangeira & Fala, escrita, redação... \\
\hline Conhecimento de ferramentas CAD & Solidworks, AutoCad... \\
\hline Conhecimento programação. & Excel, Matlab... \\
\hline Conhecimento em computação básica & $\begin{array}{l}\text { Trabalhar com arquivos de computadores, fazer } \\
\text { downloads e instalações de softwares, navegar na } \\
\text { internet... }\end{array}$ \\
\hline $\begin{array}{l}\text { Conhecimento em ferramentas de } \\
\text { divulgação }\end{array}$ & $\begin{array}{l}\text { Cartazes, plataformas online, design de websites, } \\
\text { gestão de mídias sociais... }\end{array}$ \\
\hline $\begin{array}{l}\text { Conhecimento de ferramentas } \\
\text { mecânicas }\end{array}$ & $\begin{array}{l}\text { Chaves de fenda, martelos, tesouras, tornos } \\
\text { mecânicos, brocas, fresadoras... }\end{array}$ \\
\hline $\begin{array}{l}\text { Conhecimento em gestão financeira } \\
\text { Saber comprar, saber onde deve investir dinheiro, } \\
\text { saber com o que gastar }\end{array}$ \\
\hline
\end{tabular}

Fonte: Próprio autor. 
$\mathrm{Na}$ tabela 4 estão representadas as qualidades pessoais do indivíduo. Esse grupo de habilidades diz respeito a individualidade de cada aluno, e é necessário que o aluno exercite o autoconhecimento, para cada vez mais aprimorar essas habilidades.

Tabela 4 - Qualidades pessoais

\begin{tabular}{l|l}
\hline $\begin{array}{l}\text { Competência } \\
\text { habilidade }\end{array}$ & Descrição. \\
\hline Competência & $\begin{array}{l}\text { Habilidade para cumprir uma tarefa e de fazer o trabalho } \\
\text { solicitado com qualidade }\end{array}$ \\
\hline Compromisso & Se dedicar ao máximo à realização de sua tarefa \\
\hline Tolerância & $\begin{array}{l}\text { Capacidade de resistir, suportar as pressões que surgem no } \\
\text { ambiente de trabalho, aceitar opiniões contrárias as suas }\end{array}$ \\
\hline Organização & Ser uma pessoa organizada, dentro e fora da atividade \\
\hline Pontualidade & Capacidade de cumprir tarefas, e estar sempre no horário \\
\hline Flexibilidade & Habilidade de se adaptar a mudanças \\
\hline Cordialidade & Ser uma pessoa de fácil aproximação, ser uma pessoa amigável \\
\hline Compromisso & de \\
aprendizagem contínua & Ser uma pessoa condicionada a buscar informações adicionais \\
\hline Espírito competitivo & Gostar de desafios, de superar os próprios limites... \\
\hline Criatividade & Habilidade de criar coisas novas, empreender novas ideias... \\
\hline Motivação & Gostar do que faz e sonhar com algo relacionado à atividade \\
\hline Competência & $\begin{array}{l}\text { Habilidade para cumprir uma tarefa e de fazer o trabalho } \\
\text { solicitado }\end{array}$ \\
\hline
\end{tabular}

Fonte: Próprio autor.

Tabela 5 - Trabalho em equipe

\begin{tabular}{l|l}
\hline $\begin{array}{l}\text { Competência } \\
\text { habilidade }\end{array}$ & Descrição. \\
\hline Trabalho em equipe & $\begin{array}{l}\text { Confiança e lealdade na sua equipe, acreditar nas pessoas que } \\
\text { estão trabalhando com você }\end{array}$ \\
\hline $\begin{array}{l}\text { Noções de cidadania e e } \\
\text { ética }\end{array}$ & $\begin{array}{l}\text { Conhecimento dos direitos, deveres e dos limites de atuação que } \\
\text { você tem, dentro da sociedade e dentro do campo de trabalho }\end{array}$ \\
\hline Gestão de pessoas & Atribuir tarefas ás pessoas de acordo com suas qualidades \\
\hline $\begin{array}{l}\text { Capacidade de tomar } \\
\text { decisões }\end{array}$ & $\begin{array}{l}\text { Saber enxergar o que é melhor para o grupo, saber decidir quando } \\
\text { há várias opções de solução, sem ceder às pressões. }\end{array}$ \\
\hline Busca de apoio externo & $\begin{array}{l}\text { Capacidade de negociar com grupos externos, buscar patrocínio, } \\
\text { buscar apoio jurídico, envolver pessoas externas a apoiar a } \\
\text { atividade }\end{array}$ \\
\hline
\end{tabular}

Fonte: Próprio autor 


\section{RESULTADOS}

Na Figura 1-Média das notas para conhecimentos teóricos está demonstrado que as atividades Aerodesign e DPE são as que mais demandam fundamentos em ciências, o mesmo ocorre na habilidade de aplicar equações matemáticas. Em ambas as atividades o objetivo é construir um protótipo que irá desafiar as leis físicas, então essas habilidades tornam-se necessárias.

Para todas as atividades é importante o aluno saber pesquisar informações. Muitas vezes nas atividades DPE e Aerodesign, consegue-se bons resultados buscando informações em websites, artigos científicos, teses acadêmicas e outros.

Para todas as atividades, exceto grêmio, o conhecimento na área de atuação é também muito importante, pois o aluno já ingressa sabendo sobre o que irá aprender.

Outro aspecto que se deve notar, é que todas as atividades consideram ter um bom RSG pouco importante ou sem importância, ao contrário das iniciações cientificas, que muitas vezes exigem do aluno um bom RSG para o ingresso.

Figura 1-Média das notas para conhecimentos teóricos

\section{Conhecimentos teóricos}

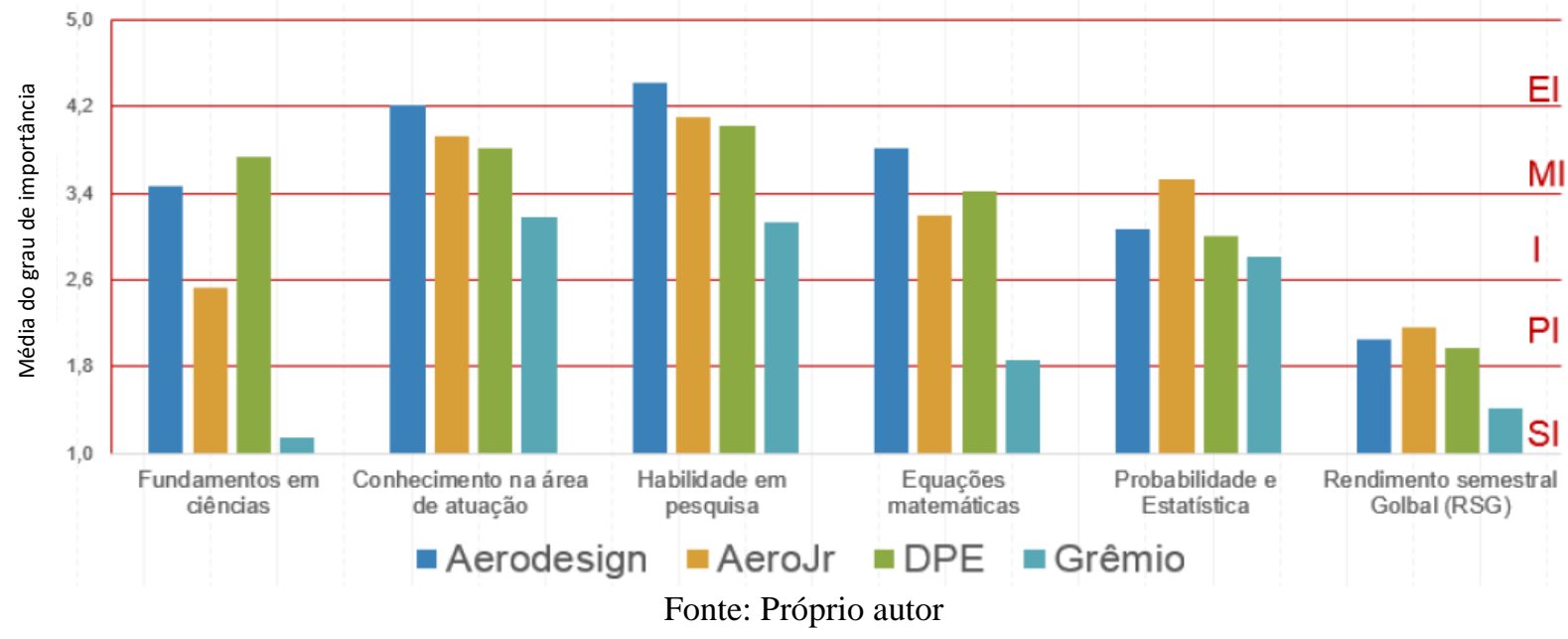

Na Figura 2 - Média das notas para conhecimentos práticos e de engenhariaestão ilustrados os resultados sobre os conhecimentos práticos e de engenharia. O conhecimento de projeto é muito importante para as atividades Aerodesign e DPE, pois nas competições que disputam, um dos critérios avaliativos é o projeto do protótipo, o que vai demandar do aluno um aperfeiçoamento maior dessa habilidade para obter melhores resultados nas competições.

As habilidades em conhecimento de custos são muito importantes, principalmente para as atividades Grêmio e AeroJr, que funcionam basicamente como empresas. Precisam angariar recursos e investi-los para melhor funcionamento/desempenho de suas atividades.

Todas as atividades requerem uma boa habilidade em identificar e resolver problemas, principalmente a AeroJr, que tem como fundamental proposta a consultoria de serviços. $\mathrm{O}$ Aerodesign e DPE também se destacam nessa habilidade, visto que sempre fazem testes nos seus protótipos, e quando ocorre algum problema, precisam identificá-lo com agilidade e resolver em tempo limitado para as competições.

Os conhecimentos em técnicas de processos de fabricação são muito mais valiosos para as atividades do Aerodesign e DPE do que para as demais, principalmente porque essas atividades têm como objetivo central a fabricação de um protótipo funcional. 


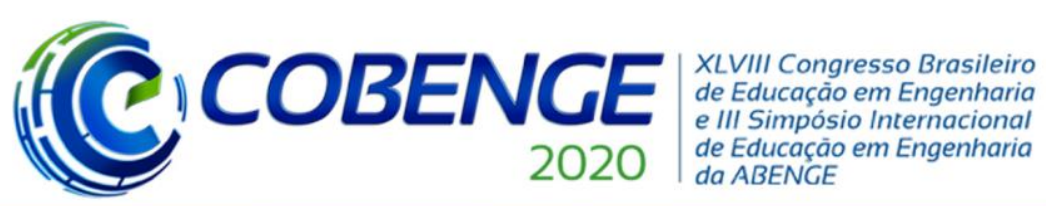

"Os desafios para formar hoje o engenheiro do amanhã"
$\mathrm{Ol}$ a $\mathrm{O} 3$ de dezembro

Evento On-line

Figura 2 - Média das notas para conhecimentos práticos e de engenharia

\section{Conhecimento Prático e de Engenharia}

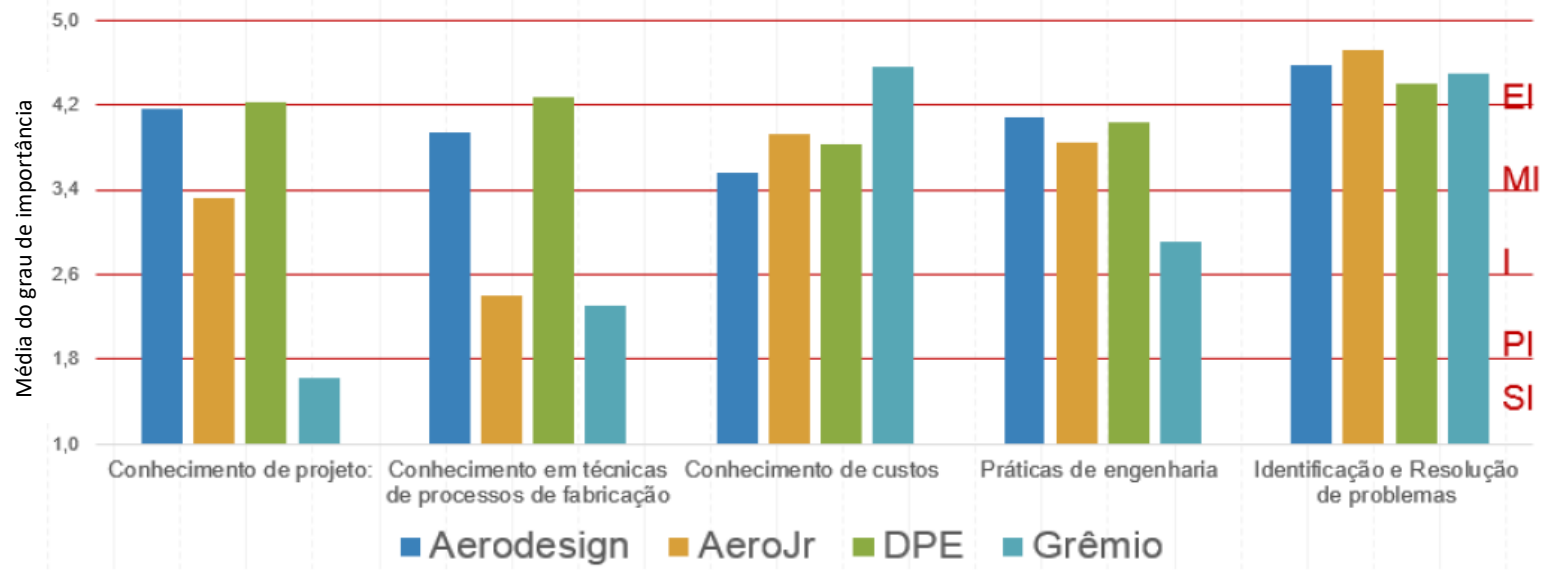

Fonte: Próprio autor

Na Figura 3 estão ilustrados os resultados para conhecimento de ferramental. Nessa categoria existem grandes contrastes. Enquanto DPE e Aerodesign precisam saber trabalhar com ferramentas CAD, programação e ferramentas mecânicas, devido natureza dessas atividades, Grêmio e AeroJr precisam mais que o estudante tenha conhecimentos em ferramentas de divulgação e gestão financeira. Novamente ressaltando o caráter empresarial dessas duas atividades.

Já quando se trata da habilidade de conhecimentos em língua portuguesa, o grêmio e AeroJr consideram essa muito importante, pois muitas vezes nessas atividades, precisam elaborar contratos, editais, cartas. Isso torna muito importante o domínio da língua escrita e falada. Todas as atividades precisam que o aluno tenha boas habilidades em computação básica.

Figura 3 - Média das notas para conhecimento de ferramental

\section{Conhecimento de Ferramental}

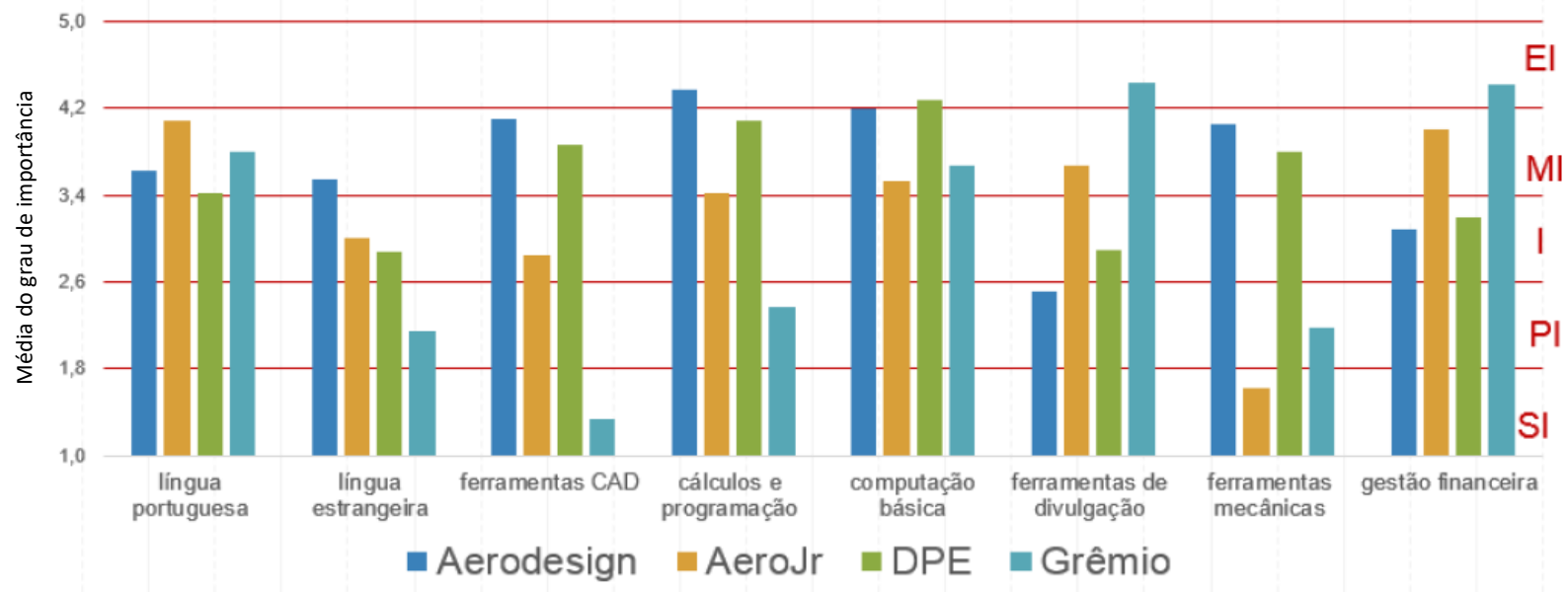

Fonte: Próprio autor

$\mathrm{Na}$ Figura 4 estão ilustrados os resultados para qualidades pessoais. Em todas as atividades extracurriculares o critério mais importante para o ingresso de um aluno é o 
(C) COBENGE

"Os desafios para formar hoje o engenheiro do amanhã"

comprometimento e a motivação com aquele grupo e atividade. Por isso, em todas as atividades a motivação foi colocada como muito importante ou extremamente importante. Curiosamente, um fator comum e considerado fundamental para um aluno ingressar em qualquer uma dessas atividades, é o grau de comprometimento que ele está disposto a dedicar, e a motivação para poder fazer parte da equipe.

Para o Grêmio e AeroJr, a proatividade se destaca, pois, seus membros são livres para desenvolverem suas tarefas não tendo um objetivo específico, logo a proatividade ajuda a encontrar novos objetivos. Enquanto o Aerodesign e DPE estão sempre em busca de um objetivo bem definido, assim, é preciso ter flexibilidade para negociar seus recursos e chegar o mais próximo do seu objetivo, que é a vitória nas competições.

Para o grêmio, ter cordialidade é muito importante, pois, o seu papel principal é promover a integração/interação dos alunos do curso. Para a AeroJr, cordialidade atrai novos clientes e oportunidades de negócios.

Empatia é muito importante para o Grêmio, pois esse desempenha um papel de representar os alunos, sendo assim precisa entender bem as particularidades de cada aluno.

Figura 4 - Média das notas para qualidades pessoais

\section{Qualidades Pessoais}

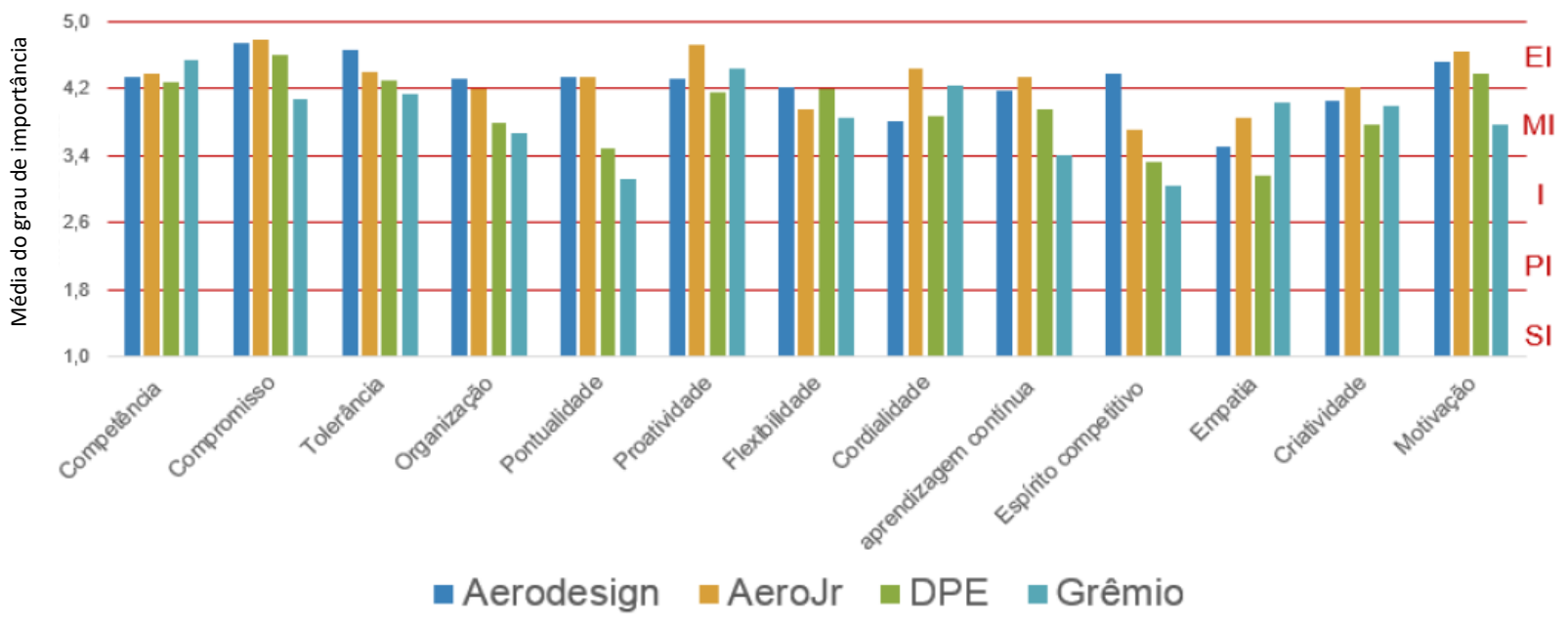

Fonte: Próprio autor

Na Figura 5 estão ilustrados os resultados para o grupo de habilidades de trabalho em equipe. Todas atividades consideraram pelo menos muito importante todas as habilidades.

Gestão de pessoas para a AeroJr é extremamente importante, pois desempenha o papel de intermediar os problemas dos clientes para a pessoa com capacitação técnica resolver, mediando os interesses do cliente e do prestador de serviços.

E para o Grêmio é extremamente importante ser capaz de tomar decisões, uma vez que essas decisões afetam diretamente a vida acadêmica de todos os alunos e professores do curso. 
Figura 5 - Média das notas para trabalho em equipe

\section{Trabalho em Equipe}

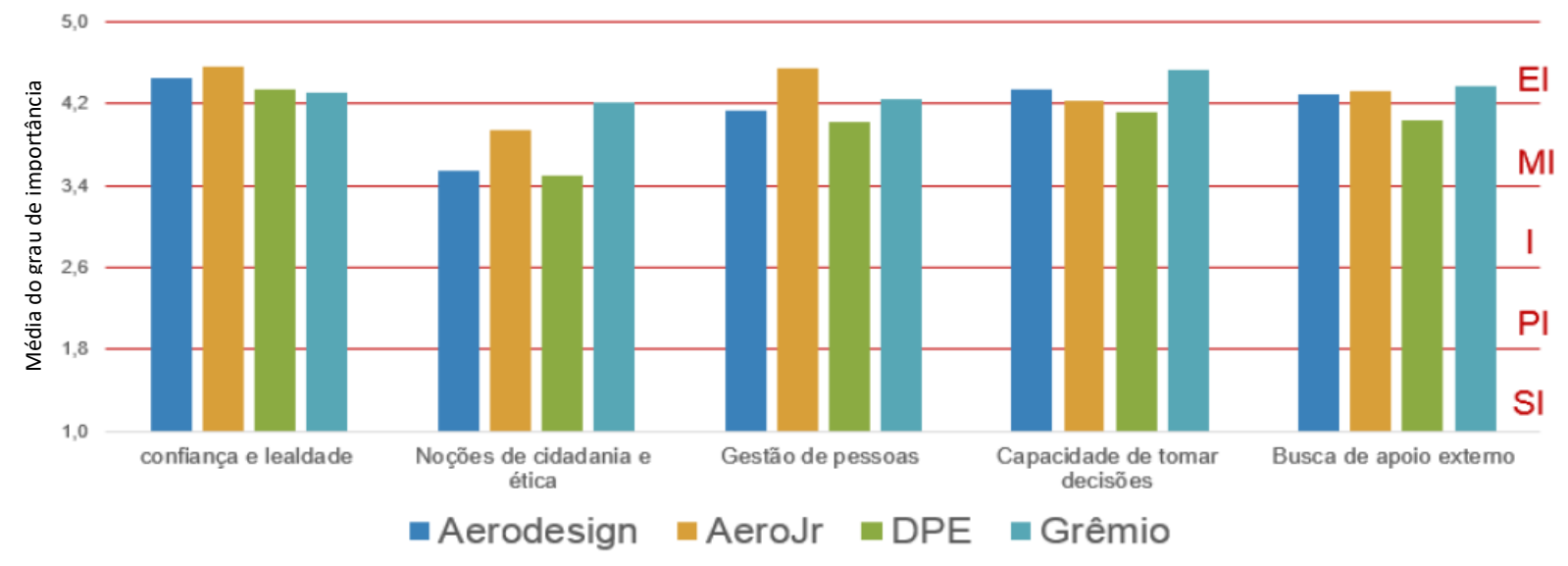

Fonte: Próprio autor

\section{CONCLUSÕES}

A partir dos resultados das 76 entrevistas é possível traçar um perfil sobre o aluno que participa dessas atividades extracurriculares. Esse aluno valoriza muito o trabalho em equipe, tendo como valor principal da equipe a confiança e a lealdade. Além disso, é muito valorizado o indivíduo que é compromissado com a equipe, que seja proativo, que tente resolver as tarefas com qualidade e que principalmente esteja motivado a fazer parte do grupo. E por fim, o aluno que participa dessas atividades, espera-se que ele tenha/aprimore a capacidade de identificar e resolver problemas.

Por outro lado, os alunos pertencentes a todas essas atividades extracurriculares classificaram como pouco importante ou sem importância ter um bom desempenho nas disciplinas acadêmicas, o que no gráfico foi mostrado como RSG acima de 3,0 (notas acima de 70\%). Em contraste, as habilidades em pesquisa e identificação e resolução de problemas foram consideradas muito importante ou extremamente importante para todos os grupos de atividades. $\mathrm{O}$ que sugere que os alunos ou veem pouca relação do conteúdo acadêmico com o que se pratica nessas atividades, ou que apenas conteúdo acadêmico não é suficiente para desempenharem bem as atividades extracurriculares.

\section{REFERÊNCIAS}

FERREIRA, Ronaldo da Silva. Tendências curriculares na formação do engenheiro do ano 2000. IN: LINSINGEN, Irlan Von et al. Formação do Engenheiro: desafios da atuação docente, tendências curriculares e questões da educação tecnológica. Florianópolis: Editora da UFSC, 1999.

VERTICCHIO, Norimar de Melo. Análise comparativa das habilidades e competências necessárias para o engenheiro na visão da indústria, dos discentes e dos docentes. 2006. 180f. Dissertação (Mestrado) - Escola de Engenharia, Universidade Federal de Minas Gerais, Belo Horizonte, 2006.

SILVA, D. da. O engenheiro que as empresas querem hoje. In: LINSINGEN, Irlan Von; et al. Formação do Engenheiro. Florianópolis, Editora da UFSC, 1999. 


\title{
INSTRUCTIONS FOR PREPARATION AND SUBMISSION OF WORKS TO THE SCIENTIFIC COMMITTEE OF XLVI BRAZILIAN CONGRESS OF ENGINEERING EDUCATION
}

\begin{abstract}
: extra classes activities have been playing a fundamental role in the development/improvement of some competencies and skills in the training of engineering students. This work aims to understand which activities help in the development of which skills for the student. The profile of the student who wants to participate in activities outside the scope of the classroom, is that of a student who cares little for academic performance, and who seeks to be loyal to a team to which he will be a part and to have a level of commitment and motivation that allows him to have good results in the tasks that he will perform.
\end{abstract}

Keywords: Skills and abilities. Extra classes activities. Aerospace engineering course 